Past, Present, and Future Roles of Long-Term Experiments in the LTER Network Author(s): Alan K. Knapp, Melinda D. Smith, Sarah E. Hobbie, Scott L. Collins, Timothy J. Fahey, Gretchen J. A. Hansen, Douglas A. Landis, Kimberly J. La Pierre, Jerry M. Melillo, Timothy R. Seastedt, Gaius R. Shaver and Jackson R. Webster

Reviewed work(s):

Source: BioScience, Vol. 62, No. 4 (April 2012), pp. 377-389

Published by: University of California Press on behalf of the American Institute of Biological Sciences

Stable URL: http://www.jstor.org/stable/10.1525/bio.2012.62.4.9

Accessed: 02/07/2012 12:15

Your use of the JSTOR archive indicates your acceptance of the Terms \& Conditions of Use, available at http://www.jstor.org/page/info/about/policies/terms.jsp

JSTOR is a not-for-profit service that helps scholars, researchers, and students discover, use, and build upon a wide range of content in a trusted digital archive. We use information technology and tools to increase productivity and facilitate new forms of scholarship. For more information about JSTOR, please contact support@jstor.org. 


\title{
Past, Present, and Future Roles of Long-Term Experiments in the LTER Network
}

\author{
ALAN K. KNAPP, MELINDA D. SMITH, SARAH E. HOBBIE, SCOTT L. COLLINS, TIMOTHY J. FAHEY, \\ GRETCHEN J. A. HANSEN, DOUGLAS A. LANDIS, KIMBERLY J. LA PIERRE, JERRY M. MELILLO, \\ TIMOTHY R. SEASTEDT, GAIUS R. SHAVER, AND JACKSON R. WEBSTER
}

The US National Science Foundation-funded Long Term Ecological Research (LTER) Network supports a large (around 240) and diverse portfolio of long-term ecological experiments. Collectively, these long-term experiments have (a) provided unique insights into ecological patterns and processes, although such insight often became apparent only after many years of study; (b) influenced management and policy decisions; and (c) evolved into research platforms supporting studies and involving investigators who were not part of the original design. Furthermore, this suite of long-term experiments addresses, at the site level, all of the US National Research Council's Grand Challenges in Environmental Sciences. Despite these contributions, we argue that the scale and scope of global environmental change requires a more-coordinated multisite approach to long-term experiments. Ideally, such an approach would include a network of spatially extensive multifactor experiments, designed in collaboration with ecological modelers that would build on and extend the unique context provided by the LTER Network.

Keywords: climate change, global change, long-term research, LTER Network, multifactor experiments

M ore than $\mathbf{3 0}$ years ago, Odum (1977) described ecology as a uniquely integrative and synthetic scientific endeavor, and the diversity of research approaches employed today reflects this perspective (e.g., Rees et al. 2001). Collectively, ecologists conduct research that includes virtually every ecosystem type on Earth, with studies that span a broad range of spatial and temporal scales. Moreover, the most successful research programs generally employ a mixture of complementary approaches, including retrospective studies, observations, experiments (natural and manipulative), gradient studies, synthetic analyses, and modeling. The research portfolios of the 26 sites within the US National Science Foundation (NSF)-funded Long Term Ecological Research (LTER) Network (http://lternet.edu) exemplify this spatially and temporally extensive and multifaceted approach to ecology (Hobbie et al. 2003), although the degree to which the sites allocate time and resources to particular research approaches varies on the basis of the questions being addressed, site-specific constraints, and the culture of the discipline (e.g., oceanographers study systems differently than do forest ecologists).

Site-based manipulative experiments have long been a cornerstone of ecological research. Although long-term experiments (box 1) have a foundational history in ecology (e.g., the Rothamstad fertilization study begun in 1856), short-term experiments are much more common for a variety of reasons (Tilman 1989). Short-term experiments provide information on how a system is regulated at the time and place of the manipulation (i.e., the initial limiting factors and their interactions). However, in complex systems with multiple components operating on different time scales of response, the initial trajectories of response of either the whole system or of individual components (e.g., single species) will not necessarily indicate either the direction or the magnitude of long-term change. Long-term experiments, when coupled with measurements of key processes, will be more likely to enable interpretation of the entire trajectory of system response, as well as the trajectories of change in system components (i.e., species or pools of organic matter and elements). A key difference between long-term and short-term experiments is that long-term experiments provide insight into the causes of the changes in the slope of responses, the causes of the inflection points, and the magnitude of the long-term change, whereas short-term experiments are focused only on the initial trajectories. Thus, long-term experiments can address mechanisms and temporal dynamics in a complementary fashion, particularly when the experiments are combined with other research approaches (e.g., observational and gradient studies). In doing so, they can help elucidate how historical influences 
Box 1. Definition of long-term ecological experiments.

We define experiments simply as planned or active manipulations of a single factor or of several factors (drivers or components of ecological systems) in order to test hypotheses. Such manipulations may occur at spatial scales that vary from small plots to whole systems (watersheds or entire lakes). This definition excludes consideration of natural field experiments such as those involving floods, droughts, hurricanes, wildfires, and other uncontrolled natural events, unless they can serendipitously be incorporated into a planned experimental design (see the text).

More challenging is the definition of long term. Ideally, ecological or life-history criteria (e.g., process and turnover rates, life span of organisms) or the time scales of ecological phenomena would be used to define an experiment as long term. Operationally, however, the duration of experiments, which typically require financial resources to be initiated and continued, is to a large extent constrained by funding cycles. Given the Long Term Ecological Research (LTER) Network focus of this review, we view a long-term experiment as one that is planned to exceed or already exceeds six years in length, which would span two traditional LTER Network funding cycles and is also a sufficient length to allow both mechanisms and temporal dynamics to be identified. This duration is also consistent with the requisite period of continuous measurements for support by the US National Science Foundation's Long-Term Research in Environmental Biology program.

that shape the present can be merged with a mechanistic understanding of contemporary processes to enable forecasting the future of ecological systems (Carpenter 2002). In contributing to this understanding, long-term experiments are critical for informing and validating mechanistic models and for linking short-term process studies with long-term observations to improve models for forecasting future scenarios.

Long-term experiments have been an integral part of the NSF-funded LTER program since its inception in 1980 (Callahan 1984). Indeed, the LTER program's early mission statement specifically called for the creation of a legacy of "well-designed and well-documented long-term observations, experiments, and archives of samples and specimens" (Hobbie et al. 2003, p. 22). Although there are certainly many valuable long-term experiments worldwide (Rees et al. 2001), a large and diverse collection has been developed within the US LTER Network. Now, after more than three decades of research, an assessment of the types of long-term experiments within the LTER Network and their contributions is warranted. Below, we review the motivation for and the role of long-term experiments in the LTER Network, we summarize the collective lessons learned from these long-term experiments, and we envision the future role for long-term experiments in advancing ecological science and addressing critical questions facing society as the LTER Network continues into its fourth decade.

\section{Early long-term experiments of the LTER Network}

Long-term experiments served as the basis for the establishment of the research programs at several of the initial LTER sites funded in the 1980s. For example, the AND, CWT, and HBR LTER sites (see table 1 for site abbreviations) began as US Department of Agriculture (USDA) Forest Service experimental forests. At these sites, the responses of hydrology, energy flow, and nutrient cycling to changes in forest structure caused by disturbance had been quantified experimentally using paired watersheds (e.g., Hewlett and Helvey 1970) and the small-watershed approach (Likens 1985) for a number of years prior to their being included in the LTER program (figure 1). Similarly, the USDA Agricultural Research Service established long-term livestock grazing experiments at several of their experimental ranges in the early 1900s, two of which became LTER program sites (JRN and SGS; see figure 1). The response of arctic tundra vegetation to long-term manipulations of nutrient availability and temperature (Chapin et al. 1995) also provided the foundation for continuing studies of global-change effects at the ARC site (figure 1).

Research programs at several other founding LTER sites were built around newly established long-term experiments designed to test a diverse set of hypotheses, with the expectation of a long-term funding commitment. For example, the role and mechanisms whereby soil resources regulate community structure have been examined in plot-level manipulations at the CDR site since its inception (figure 1). The long-term consequences of nitrogen $(\mathrm{N})$ deposition, climate warming, and hurricanes for nutrient cycling, carbon (C) dynamics, and forest productivity have been assessed at HFR (Foster et al. 1997). Moreover, experiments evaluating the interactions of fire, ungulate grazing, and climate variability in driving patterns and processes in tallgrass prairie formed the basis for long-term experiments at KNZ (figure 1). Finally, the core experiment in row-crop agriculture at KBS involved the long-term imposition of a gradient of varying management inputs into midwestern US cropping systems. In all cases, the expectation that key ecological responses to these manipulations might not become evident for many years justified the long-term nature of the experimental design for these LTER programs.

\section{Long-term experiments today in the LTER Network}

In order to provide a more comprehensive overview of long-term experiments in the LTER Network, we surveyed each of the 26 LTER sites (table 1) to quantify the number, types, and durations of long-term experiments supported by the LTER Network. In addition, we convened a two-day working-group meeting with participants from of a subset of LTER sites in February 2011. On the basis of responses (from $100 \%$ of the sites) to the survey questions, a total of 239 long-term experiments (completed and ongoing) were identified within the LTER Network (table 1). Of these, less than $10 \%$ exceed 30 years in duration, which indicates that most long-term experiments were initiated during the time frame of the LTER Network (figure 2). Diversity among the 


\begin{tabular}{|c|c|c|c|c|c|}
\hline Site name & Site acronym & $\begin{array}{l}\text { Year established } \\
\text { in LTER Network }\end{array}$ & $\begin{array}{l}\text { Number of } \\
\text { long-term } \\
\text { experiments }\end{array}$ & $\begin{array}{l}\text { Number of } \\
\text { multifactor } \\
\text { experiments }\end{array}$ & $\begin{array}{l}\text { Multisite } \\
\text { experiments } \\
\text { (yes }[y] \text { or no }[n] \text { ) }\end{array}$ \\
\hline Andrews Experimental Forest & AND & 1980 & 23 & 1 & $\mathrm{y}$ \\
\hline Arctic & ARC & 1987 & 10 & 7 & $\mathrm{y}$ \\
\hline Baltimore Ecosystem Study & BES & 1997 & 1 & 0 & $\mathrm{n}$ \\
\hline Bonanza Creek Experimental Forest & BNZ & 1987 & 18 & 3 & $\mathrm{y}$ \\
\hline California Current Ecosystem & CCE & 2004 & 2 & 0 & $\mathrm{n}$ \\
\hline Cedar Creek Ecosystem Science Reserve & CDR & 1981 & 36 & 9 & $\mathrm{y}$ \\
\hline Central Arizona-Phoenix & CAP & 1997 & 2 & 0 & $\mathrm{n}$ \\
\hline Coweeta Hydrological Laboratory & CWT & 1980 & 5 & 1 & $\mathrm{y}$ \\
\hline Florida Coastal Everglades & FCE & 2000 & 5 & 1 & $\mathrm{n}$ \\
\hline Georgia Coastal & GCE & 2000 & 1 & 0 & $\mathrm{n}$ \\
\hline Harvard Forest & HFR & 1988 & 18 & 2 & $\mathrm{y}$ \\
\hline Hubbard Brook Experimental Forest & HBR & 1987 & 5 & 1 & $\mathrm{n}$ \\
\hline Jornada Basin & JRN & 1981 & 15 & 2 & $\mathrm{y}$ \\
\hline Kellogg Biological Station & KBS & 1987 & 12 & 8 & $y$ \\
\hline Konza Prairie Biological Station & KNZ & 1980 & 18 & 8 & $\mathrm{y}$ \\
\hline Luquillo Experimental Forest & LUQ & 1988 & 4 & 1 & y \\
\hline McMurdo Dry Valleys & MCM & 1993 & 12 & 3 & $\mathrm{n}$ \\
\hline Moorea Coral Reef & MCR & 2004 & 1 & 1 & $\mathrm{n}$ \\
\hline Niwot Ridge & NWT & 1980 & 8 & 6 & $\mathrm{y}$ \\
\hline North Temperate Lakes & NTL & 1980 & 6 & 2 & $\mathrm{n}$ \\
\hline Palmer Station & PAL & 1991 & 0 & 0 & $n$ \\
\hline Plum Island Ecosystems & $\mathrm{PIE}$ & 1998 & 3 & 2 & $y$ \\
\hline Santa Barbara Coastal & SBC & 2000 & 1 & 0 & $y$ \\
\hline Sevilleta & SEV & 1988 & 12 & 3 & $y$ \\
\hline Shortgrass Steppe & SGS & 1981 & 17 & 4 & $y$ \\
\hline Virginia Coast Reserve & VCR & 1987 & 4 & 1 & $\mathrm{y}$ \\
\hline
\end{tabular}

experiments was manifest in the wide array of resources and environmental factors manipulated (e.g., soil nutrients, water, and temperature were the most commonly manipulated, carbon dioxide $\left[\mathrm{CO}_{2}\right]$ more rarely), as well as alterations in biotic attributes (e.g., species removal and additions, herbivory) and disturbance regimes (e.g., fire, logging, windstorms, pathogen outbreaks; figure 2). However, in only $28 \%$ (66 of 239) of the long-term experiments was more than one of these factors manipulated concurrently (table 1). As befits the chronic nature of many global-change drivers (Smith et al. 2009), the number of sites that employed press (i.e., continuous alteration) treatments in long-term experiments was $80 \%$, with $75 \%$ also supporting long-term pulse experiments. Collectively, all of the Grand Challenges for the environment identified by the National Research Council (NRC 2001) are being addressed across the LTER Network, although long-term experiments related to infectious disease are notably underrepresented (figure 2). Finally, a majority of the sites (16 of 26) participated in multisite or networklevel experiments (i.e., experiments that spanned multiple sites), which may or may not have included other LTER sites. Notable examples include the Nutrient Network, the Long-Term Intersite Decomposition Team (LIDET), and the International Tundra Experiment.

Our assessment of long-term experiments during the working-group meeting revealed that many of the earliest long-term experiments were designed as single-factor manipulations with the goal of gaining an improved understanding of the long-term nature of change (primarily at the process level) in response to either short-term (pulse) or long-term (press) manipulations. In the early years of LTER, assessing recovery from disturbance using pulse experiments 

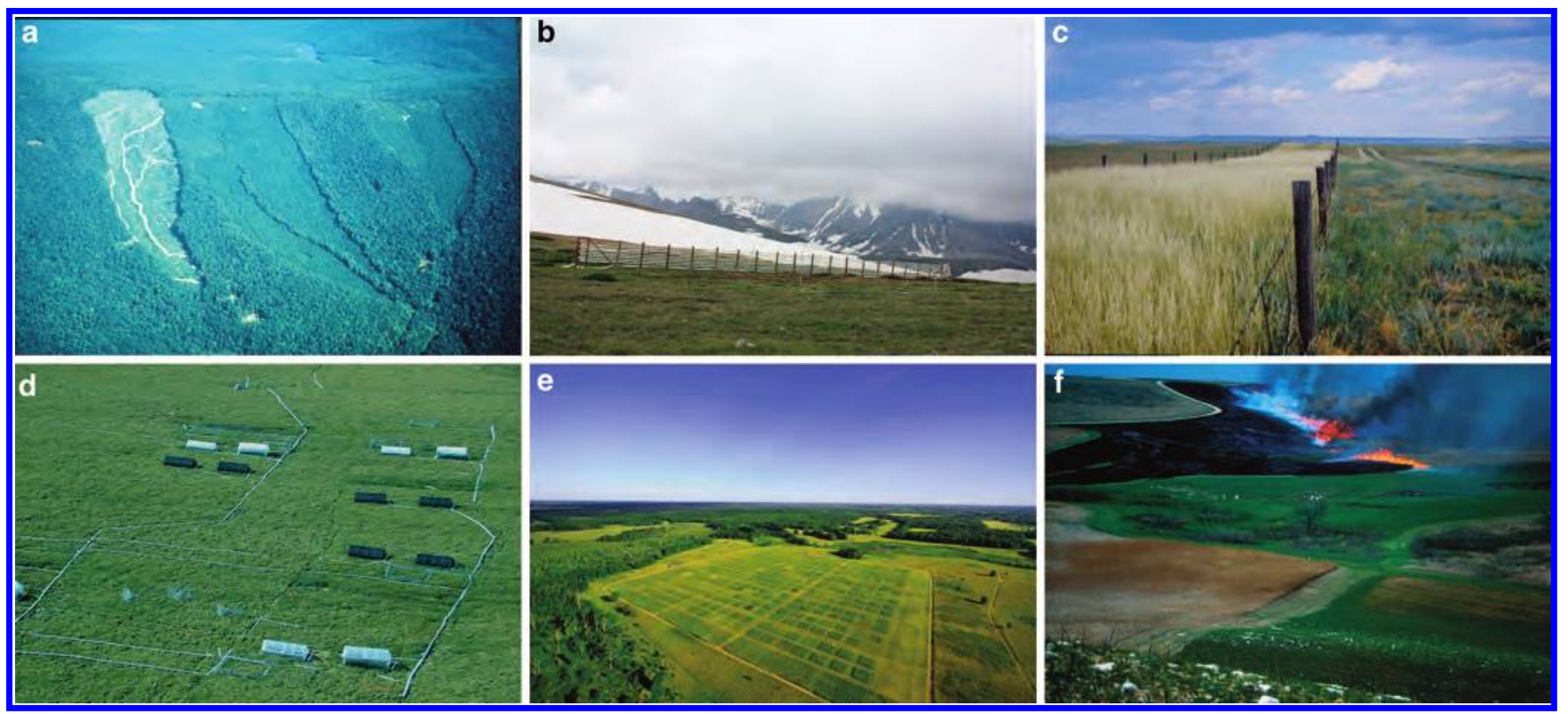

Figure 1. Examples of the diversity of long-term experiments established or already ongoing in the earliest cohorts of sites (more than 20 years old; see table 1) in the Long Term Ecological Research (LTER) Network. (a) Small watersheds with different forest harvest treatments at the HBR site (photograph: Hubbard Brook Research Foundation); (b) snowfence experiment designed to alter soil moisture and growing-season length at the NWT site (photograph: Mark Williams, Niwot Ridge LTER Program, University of Colorado); (c) a long-term ungrazed exclosure (left) adjacent to a grazed grassland at the SGS site (photograph: Alan K. Knapp); (d) warming, nutrient addition, and shade experiments at the ARC site (photograph: Sarah E. Hobbie); (e) biodiversity manipulations at the CDR site (photograph: David Tilman); (f) watershed-scale fire experiments at the KNZ site (photograph: Alan K. Knapp). Site abbreviations are defined in table 1.

(i.e., a single perturbation or manipulation event) was the most common type of experiment (Callahan 1984), such as deforestation studies at HBR and CWT or wind-disturbance studies at HRF. These studies were motivated by the need to develop or test theory in order to enable a deeper understanding of the ways in which key drivers altered ecosystem structure and function. The goal was to complement historical observations with knowledge and insight that were unattainable from traditional short-term experiments and space-for-time studies. Other experiments were initiated to understand the impacts of anthropogenic disturbances such as logging, grazing, and acid deposition. Although the initial focus was on disturbances, the more-recent trend is for long-term experiments to have stronger relevance to global-change drivers or to be linked explicitly to policy and major issues in natural-resource management (figure 3). The working group concluded that, given the number and diversity of long-term experiments in the LTER Network, Callahan's (1984) vision of the LTER Network as one that could address the "serious contradiction between the time scales of many ecological phenomena and the support to finance their study" (p. 363) has been fulfilled.

\section{Synergies between the LTER Network and long-term experiments}

Although long-term experiments have been supported by many other programs and have been conducted successfully at a wide range of sites around the globe, long-term experiments conducted at LTER sites have many important advantages. First, long-term measurements at LTER sites provide essential context for interpreting experimental responses. Long-term observations can also provide pretreatment and reference-system data, as well as the basis for identifying ecological surprises, such as extreme climatic events (Lindenmayer et al. 2010, Smith 2011). Such data are critical for interpreting experimental results over a background of natural variability-for separating signal from noise; however, these data sets are usually impossible to maintain through typical funding programs. At the HBR site, for example, researchers were able to quantify the magnitude of soil calcium $(\mathrm{Ca})$ depletion caused by twentieth-century acid deposition only through 40 years of continuous biogeochemical measurements (Likens et al. 1996). These observations, in turn, inspired a long-term experiment in which soil $\mathrm{Ca}$ availability was returned to preindustrial levels (figure 3), with the long-term trajectory of forest biomass and demography providing the context for interpreting responses to the experimental treatment. The dramatic recovery of growth, health, and regeneration of sugar maple (Acer saccharum) in response to a moderate increase in soil Ca provided further evidence that humaninduced soil Ca depletion has caused a widespread decline in this highly valued forest tree and in forest productivity overall (Juice et al. 2006). In this case, the deployment of a 


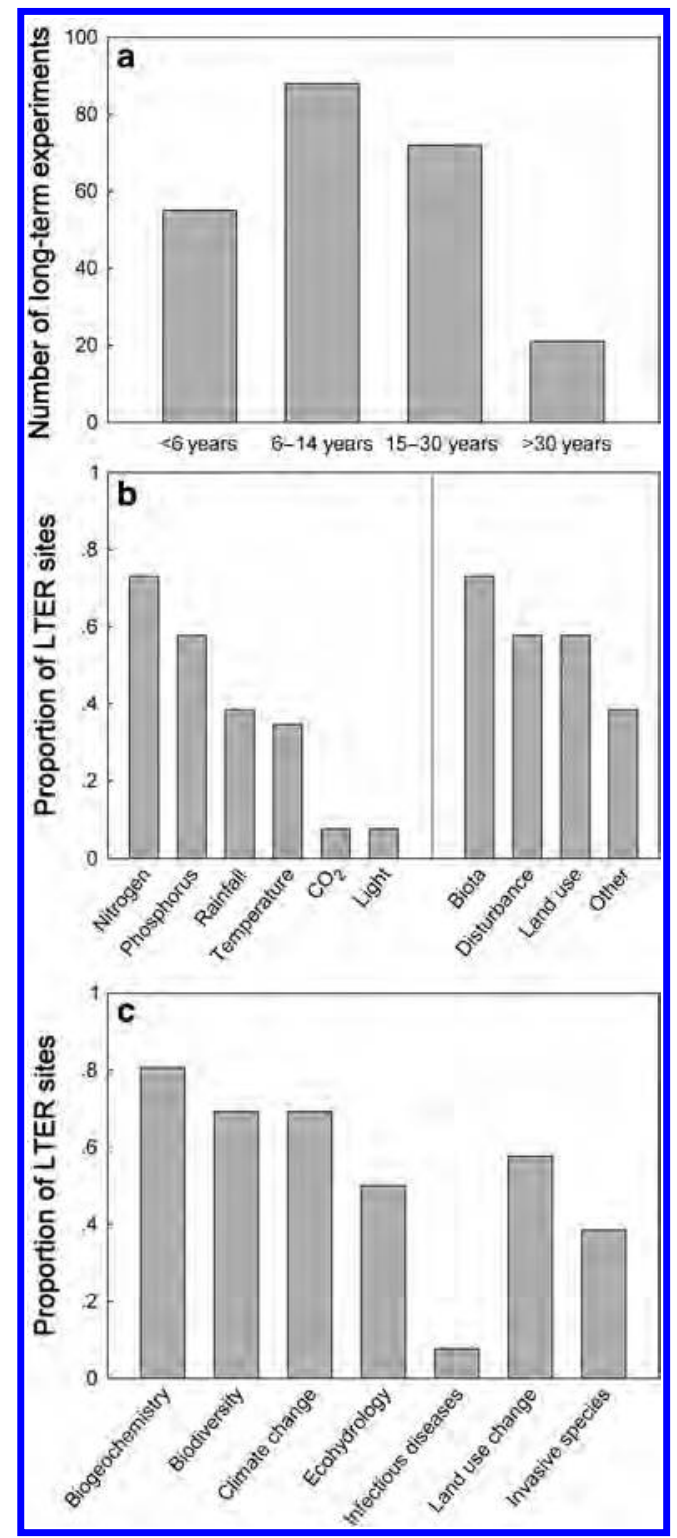

Figure 2. (a) The number of long-term experiments across the 26 Long Term Ecological Research (LTER) Network sites according to their duration. Experiments more than 30 years in duration were initiated prior to the existence of the LTER Network, whereas those less than 6 years in duration have been recently initiated with plans for continuation for more than 6 years. (b) Proportion of sites in the LTER Network with long-term experiments in which different types of factors were manipulated. Resource manipulations are in the left side of the panel, and other types of manipulations are shown in the right side (Biotic = species removals/additions, herbivory, etc.; Disturbance $=$ fire, hurricane simulation, etc.; Land use = agriculture, forest clear-cutting, etc.; Other = salinity, soil pH, etc.). (c) Proportion of LTER Network sites with long-term experiments in which the National Research Council's Grand Challenges in Environmental Sciences (NRC 2001) were addressed. These data are from a survey of all 26 LTER Network-site principal investigators (see table 1). highly sensitive tracer in the Ca treatment provided additional insights into the pathways of Ca flux through forested watersheds (Dasch et al. 2006).

In addition to long-term observations revealing patterns and inspiring experimentation to elucidate mechanisms, post-experiment monitoring at LTER sites can improve understanding and prompt the design of new studies (Janzen 2009). For example, a decade following the cessation of 10 years of experimental $\mathrm{N}$ additions at the CDR site, species richness had recovered, whereas other aspects of community structure had not. This led to a short-term experiment in which the manipulation of soil $\mathrm{N}$ availability, plant litter, and seed dispersal revealed the mechanisms related to recovery from chronic $\mathrm{N}$ fertilization (Clark and Tilman 2010). Similarly, ecosystem recovery was monitored for 10 years following 6 years of experimental acidification of Little Rock Lake (part of the NTL site) in northern Wisconsin (figure 3). This monitoring revealed that total zooplankton biomass recovered in one year, but community composition exhibited sustained differences. Approximately $40 \%$ of zooplankton taxa exhibited a lag in recovery after $\mathrm{pH}$ returned to the levels at which a biological response was first observed (Frost et al. 2006). Continued monitoring of the recovery of this system revealed complex trophic interactions and hysteresis effects-responses that would not have appeared with only a year or two of posttreatment measurements. Such opportunities arise because LTER Network sites provide consistent access to instrumentation and infrastructure, stable funding levels, and well-trained personnel who are available to continue the measurements. Furthermore, the information-management capabilities of LTER Network sites ensure that data will be collected using consistent protocols and will be archived and readily available for use by other researchers (Ingersoll 1997). Easily accessible data with well-documented metadata facilitate cross-site comparisons that are integral for expanding the results of experiments to broader spatial scales.

\section{The value of long-term ecological experiments}

On the basis of the working-group meeting and the broader site survey, we highlight below the diverse array of insights and contributions provided by long-term ecological experiments within the LTER Network. Our goal is to extend our review beyond the core scientific benefits of this suite of studies to include unique opportunities and broader impacts afforded by these long-term experiments.

Insights into long-term responses. Obviously, but not trivially, one of the greatest scientific benefits of long-term site-based experiments is that they elucidate how ecological systems respond to experimental treatments over the long term. Indeed, such experiments have repeatedly demonstrated that long-term responses to treatments can differ markedly from short-term responses (Tilman 1989, Debinski and Holt 2000). For example, in the BioCON experiment at the CDR 

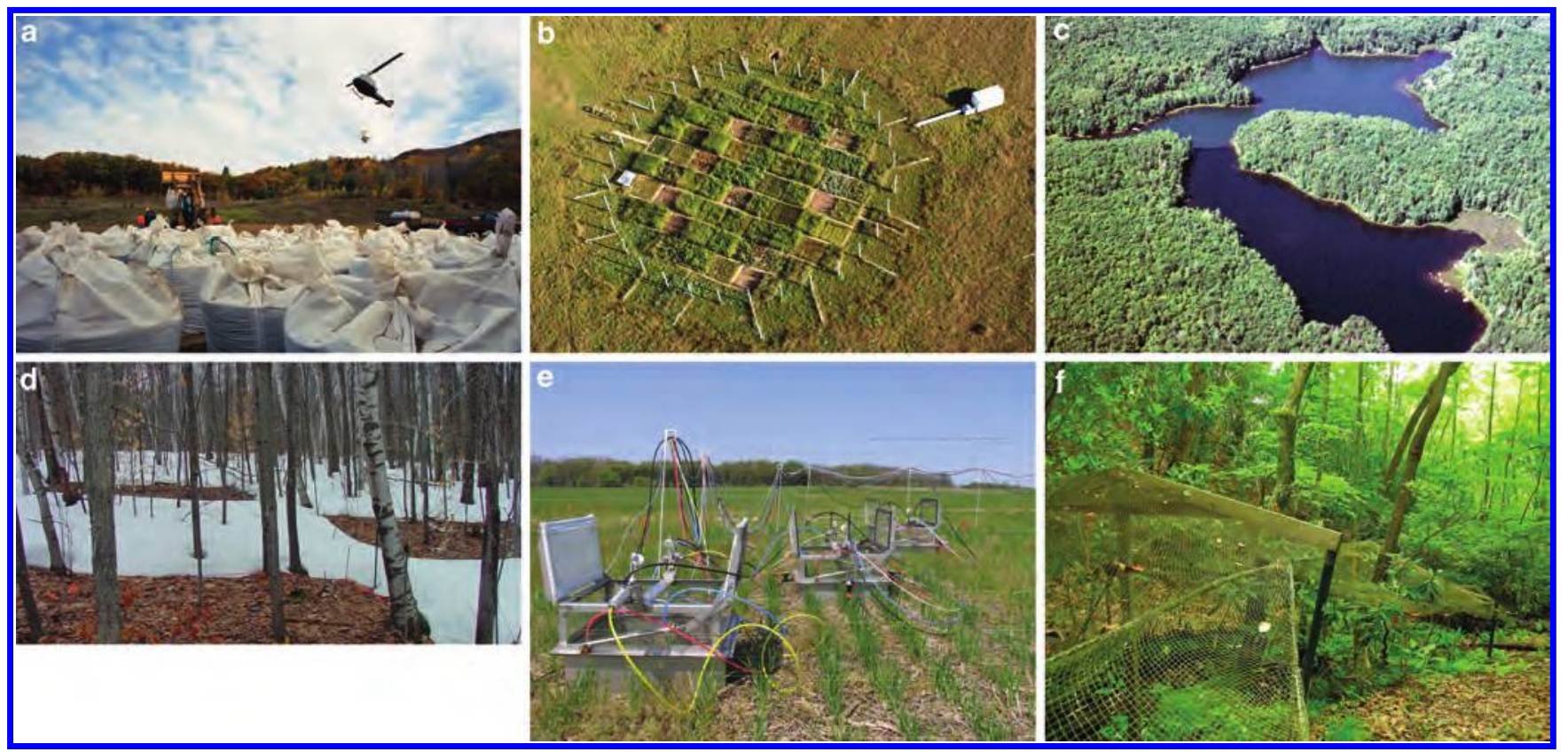

Figure 3. Examples of long-term experiments related to global change in the Long-Term Ecological Research (LTER) Network. (a) Application of calcium silicate to an experimental watershed at the HRB site to mechanistically examine acid-rain impacts (photograph: US Forest Service); (b) the multifactor BioCON experiment at the CDR site with manipulations of carbon dioxide, nitrogen, and biodiversity (photograph: David Tilman); (c) Lake acidification curtain in a lake at the NTL site to assess whole-system impacts of changes in pH (photograph: Carl J. Watras); (d) soil-warming experiment at the HFR site (plot delineated by the lack of snow in winter; photograph: Jerry M. Melillo); (e) automated trace-gas chambers for assessing the impacts of different management practices in field crops at the KBS site (photograph: Julie E. Doll, Kellogg Biological Station LTER Program); (f) litter-exclusion experiment at the CWT site designed to allow the examination of the importance of terrestrial energy inputs into streams, which also has relevance for evaluating the impacts of mountaintop mining practices (photograph: Sue L. Eggert). Site abbreviations are defined in table 1.

site (biodiversity, $\mathrm{CO}_{2}$, and $\mathrm{N}$ are manipulated; see figure 3), Reich and colleagues (2006) tested the hypothesis that the availability of $\mathrm{N}$ would constrain the response of productivity in an $\mathrm{N}$-poor grassland community to elevated $\mathrm{CO}_{2}$. Although this hypothesized interaction between $\mathrm{N}$ and $\mathrm{CO}_{2}$ eventually became apparent, it was not until the fourth year of treatment. If the experiment had been discontinued before the fourth year (i.e., within the time frame of typical funding cycles), researchers might have concluded that $\mathrm{N}$ availability had no effect on the response of these communities to elevated $\mathrm{CO}_{2}$. Similarly, in a manipulation of soil temperature at the HFR site (figure 3), the conclusion regarding the influence of warming on soil respiration would have been very different had the experiment ended after its first few years (figure 4). In that experiment, warming strongly increased soil respiration (by about 25\%) in the first five years of the study (Melillo et al. 2002). However, by the tenth year of treatment, the warming stimulation had declined to less than $5 \%$ above ambient controls. Conclusions based on the initial results of this experiment would have led to an overestimate of the positive feedback to climate warming resulting from enhanced soil organic matter decomposition. Elucidation of the mechanisms underlying these responses was made possible by coupling these single-factor studies with those in which soil and $\mathrm{N}$ were simultaneously manipulated, whereas additional microbial studies enhanced ecosystem-scale understanding (Contosta et al. 2011).

Occasionally, experimentally induced shifts in ecosystems can take years to appear, which can lead to ecological surprises (Lindenmayer et al. 2010), as exemplified by the long-term phosphorus (P)-addition experiment conducted at the Upper Kuparuk River, Alaska (part of the ARC site). In this case, although $\mathrm{P}$ fertilization stimulated epilithic algal production immediately, a major increase in bryophyte production (with subsequent effects on nutrient cycling and higher trophic levels) became apparent only after a decade of treatment-a response that was completely unexpected (figure 5; Slavik et al. 2004). In other instances, the lack of response even after a decade or more of treatments may lead to an important new understanding of patterns and processes. For example, inspired by the dramatic response of desert grasslands to an exclusion of small mammals in Portal, Arizona (e.g., Brown and Heske 1990), replicate small mammal exclosures were established in a number of grassland and shrubland sites, including the SEV site. Although no significant differences in vegetation composition and 


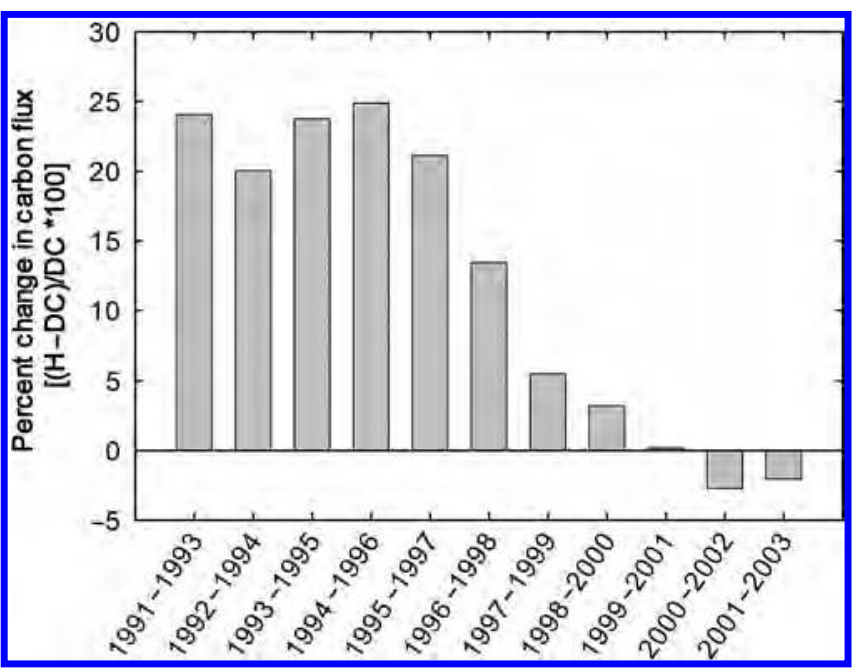

Figure 4. Long-term dynamics of soil carbon-dioxide release from the soil-warming experiment at the Harvard Forest Long-Term Ecological Research site. The data shown are the proportional change in carbon lost between soils in the heated plots ( $H$, heated by soil-warming cables) and those not warmed (but disturbed similarly to the heated plots, DC). Note that from 1991 to 1997, there was a strong effect of soil warming, but this effect diminished substantially as the experiment continued. See Melillo and colleagues (2002) for further details.

dynamics have been observed to date at the SEV site (cf. Báez et al. 2006), major changes have occurred in other aridland ecosystems (Meserve et al. 2003). The differences in responses among sites reflect the degree to which top-down control of community structure can vary among arid-land ecosystems and can prompt new experiments to better understand context dependence in the function of communities and ecosystems.

Besides elucidating how ecological responses to experimental treatments can change over time, long-term experiments can provide unique opportunities to uncover the mechanisms underlying such dynamics. In some instances, initial system responses may be dominated by the disturbance associated with initiating an experiment or because of legacies of pretreatment conditions. Therefore, it may take a while before system responses are indicative of ecological processes. For example, patterns of nitrate loss from agricultural systems that vary in management intensity are notably variable, in part because many studies are initiated before treatments have fully equilibrated or are conducted over relatively short periods of time. This has led to widely conflicting reports and little agreement about the best management practices to decrease nitrate loss. In contrast, the long-term cropping systems experiment at the KBS site (figure 3) has enabled comparisons of nitrate losses from conventional, notill, low-input, and organic cropping systems. Each of these treatments had six years to equilibrate before measurement, and they have been assessed for 11 years, which accounts for

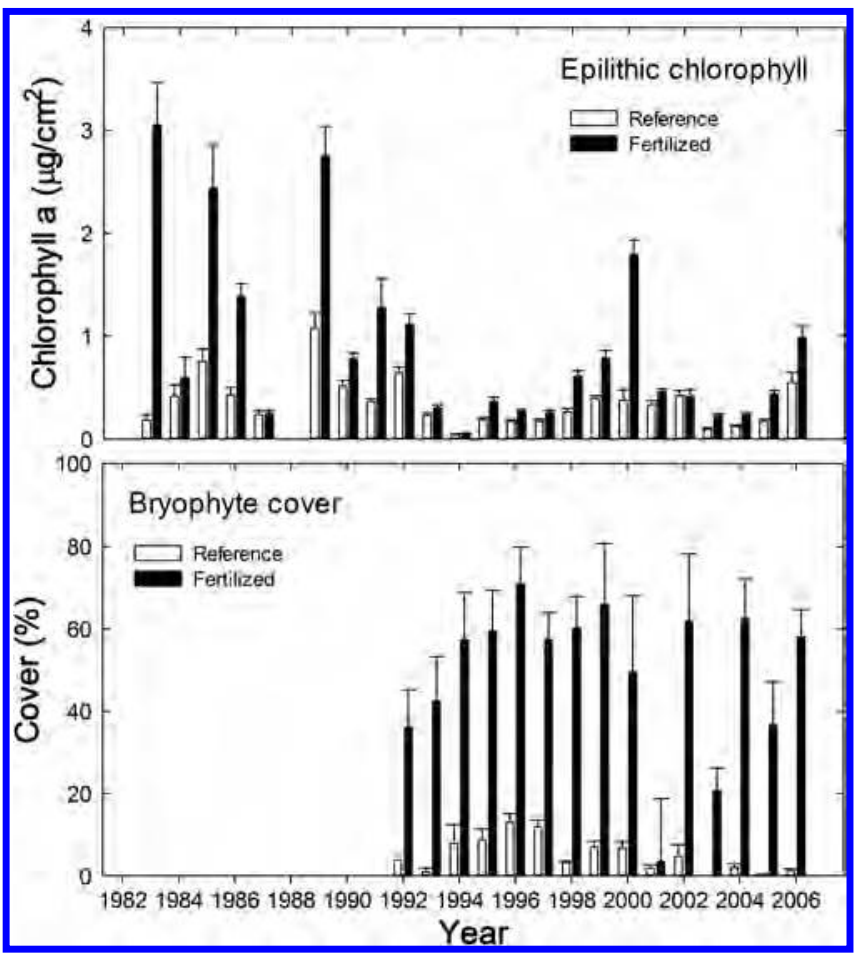

Figure 5. Long-term changes in epilitihic chlorophyll (top panel, in micrograms [ $\mu \mathrm{g}]$ per square centimeter $\left[\mathrm{cm}^{2}\right]$ ) and bryophyte cover (bottom panel, percentage) in reference and phosphorus-fertilized reaches of the Kuparuk River at the Arctic Long Term Ecological Research site. In this long-term experiment, bryophyte cover was negligible in both reference and fertilized reaches prior to 1992 but increased dramatically in response to chronic phosphorus additions afterward, with concurrent reductions in epilithic chlorophyll. The chlorophyll data are not shown in 1988 because the samples were contaminated by green algal filaments. Means are shown, and the error bars represent the positive standard error. The data are updated from Slavik and colleagues (2004).

interannual variability (Syswerda et al. 2008). This study has revealed consistent and marked differences in nitrate losses, with the low-input and organic systems having about half the nitrate losses of the conventionally managed systems.

Long-term experiments can reveal the importance of indirect effects in ecosystem processes not apparent in the short term, as well as responses that may change over the long term (Tilman 1989). At the NTL site, the experimental acidification of a small seepage lake (figure 3 ) produced numerous changes driven by indirect interactions related to changes in the food web rather than by direct consequences of lower pH. For example, the rotifer Keratella taurocephala has displayed low acid tolerance in laboratory studies but increased in density throughout the acidification experiment as a result of decreased invertebrate-predator abundance (Gonzalez and Frost 1994). Keratella taurocephala also underwent morphological changes 
in the acidified basin as a result of reduced predation pressure. Responses driven by food-web interactions were often the opposite of expectations based on laboratory studies of $\mathrm{pH}$ tolerance and generally exhibited a time lag; these unexpected results would not have been observed on time scales shorter than the response time of all trophic levels.

Other opportunities from long-term experiments. Unavoidably, long-term experiments occur against a backdrop of longterm trends; stochastic ambient conditions, including climate variability and extremes and infrequent disturbances; and changes in the abundances of predators and pathogens at scales greater than the experimental units. Although the inability to control ambient conditions can be challenging, variability in background conditions can sometimes also prove fortuitous (Tilman 1989). For example, long-term experiments can be particularly valuable if they coincide with climate or weather extremes that provide new ecological understanding. Of course, the longer an experiment is conducted, the greater the chances that ambient conditions will vary in ways that produce insights and even inspire new experiments. During the Ca-addition studies at the HBR site (figure 3), an intense ice storm damaged sugar maple trees, which allowed researchers to document improved wound repair as one of the major responses to the alleviation of Ca deficiency and, presumably, a principal mechanism underlying increased growth rates (Huggett et al. 2007). At the CWT site, Yeakley and colleagues (2003) designed an experiment to investigate the importance of riparian Rhododendron species to nutrient export to streams. They instrumented treatment and reference hillslopes, made two years of pretreatment measurements, and then removed all Rhododendron stems from a 10-meter (m) strip along $30 \mathrm{~m}$ of stream. Less than two months later, Hurricane Opal downed most of the large trees on the reference hillslope. Over the course of the study, they found that the hurricane impact on canopy trees had far greater effects on nutrient export than did the experimental Rhododendron removal. Finally, a wildfire at the KNZ site in 1991 reset most of the long-term fire treatments in the 60 watersheds at the site (figure 1) by burning them all on the same date. This afforded the opportunity to sample a large number of sites affected by the same fire but with a wide array of longer-term fire histories. This sampling revealed the importance of the amount of time since a prior fire in determining aboveground net primary productivity responses to fire (figure 6) and helped researchers interpret results from other experiments regarding the role of soil $\mathrm{N}$ in postfire responses (Blair 1997, Knapp et al. 1998).

Scientists conducting long-term experiments can also take advantage of dramatic changes in community structure, such as those resulting from extirpation or biological invasion. For example, at the KBS site, long-term monitoring of predaceous lady beetles (Coccinellidae) in experimental agricultural treatments has revealed three exotic species additions since 1988, including the multicolored Asian lady

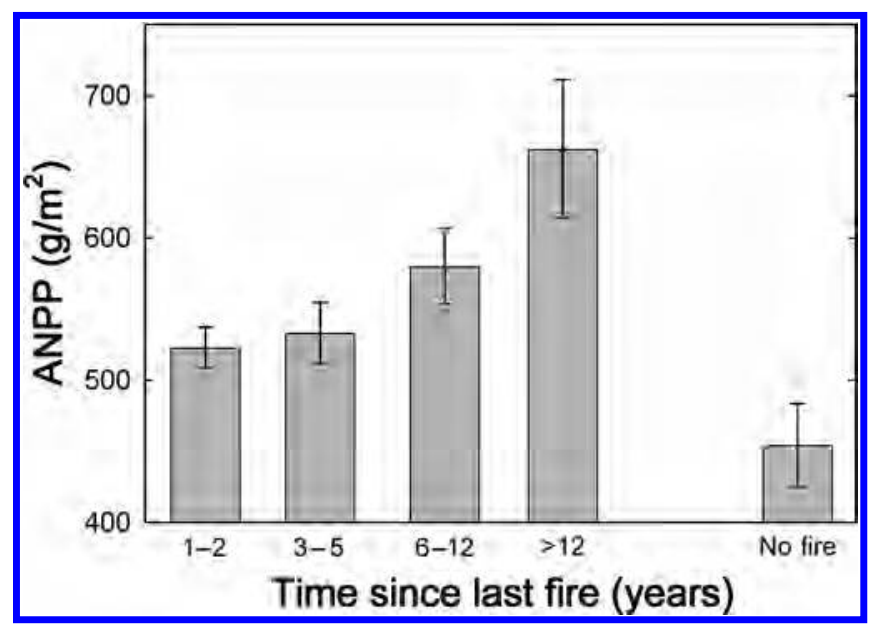

Figure 6. Response in aboveground net primary production (ANPP, in grams $[\mathrm{g}]$ per square meter $\left.\left[\mathrm{m}^{2}\right]\right)$ to a wildfire at the Konza Prairie (KNZ) Long-Term Ecological Research site. The KNZ site includes a number of watersheds that are experimentally burned at different frequencies (from annual fire to no fire). A wildfire burned most of the site in 1991 (the no-fire data are from areas that escaped the wildfire), which allowed the researchers to gain insight into how long-term fire history (including the time since the last fire) influenced ANPP responses. The mean for each time interval is displayed, and the error bars represent the standard error. Source: Adapted from Knapp and colleagues (1988).

beetle (Harmonia axyridis). The arrival of the soybean aphid (Aphis glycines) in 2000 reunited these two Asian species in a new context and resulted in surprising dynamics. Prior to 2000, $H$. axyridis was a common species; however, after 2000, it became dominant (figure 7). Moreover, it demonstrated classic predator-prey cycling with high abundances following years of aphid outbreak (Heimpel et al. 2010); process-level studies demonstrated strong top-down control of A. glycines by coccinellids (Costamagna and Landis 2006). A further surprise was that biological control of the soybean aphid was regulated by the structure of the surrounding landscape: Suppression was positively correlated with landscape diversity at the 1.5-kilometer scale (Gardiner et al. 2009).

Finally, long-term experiments can provide opportunities to address novel questions that were not part of the original motivation for the experiment. Long-term $\mathrm{N}$-enrichment studies at the ARC site were initially established as part of a broader suite of treatments designed to assess resource limitation and the response of tundra ecosystems to global-change factors (figure 1; Chapin et al. 1995). After 20 years of adding $N$, the researchers shifted their focus toward asking how much of the cumulative $\mathrm{N}$ added still remained in the plots and how this affected $\mathrm{C}$ pools (Mack et al. 2004). Somewhat surprisingly, these plots had lost significant $\mathrm{C}$, despite greater $\mathrm{C}$ inputs (net primary production) and aboveground $\mathrm{C}$ stocks with $\mathrm{N}$ addition. $\mathrm{Net}$ 


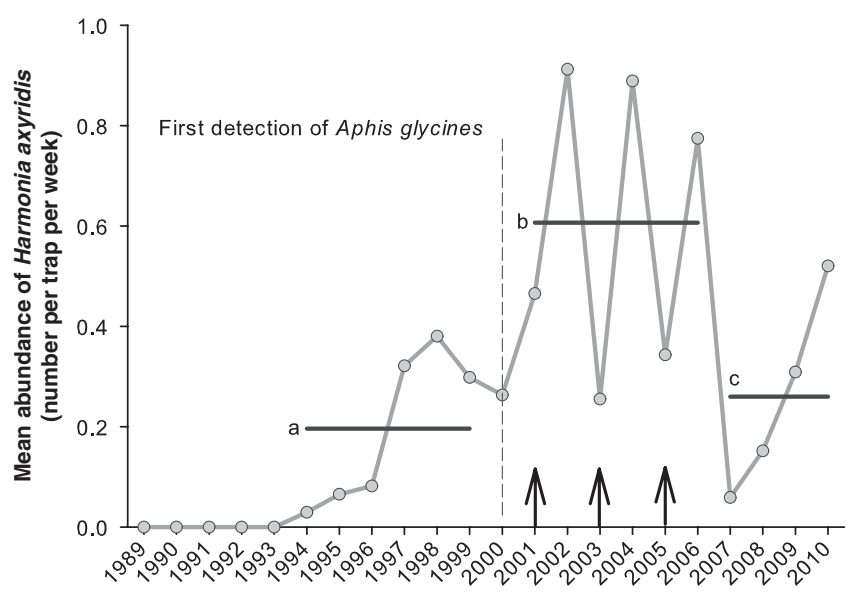

Figure 7. Abundance of adult multicolored Asian lady beetles (Harmonia axyridis) at the Kellogg Biological Station Long Term Ecological Research site from 1989 to 2010. This invasive species was first detected in 1994 and, until 1999, its mean abundance was approximately 0.2 adults per trap per week (a). Following the arrival of the soybean aphid (Aphis glycines), major aphid outbreaks (arrows) occurred every other year from 2001 to 2005, prompting strong numerical responses by Harmonia in the subsequent years and overall greater mean abundance (b). Since 2007, no aphid outbreaks have occurred, and a new pattern of intermediate Harmonia abundance may be forming $(c)$. The data are updated from Heimpel and colleagues (2010).

ecosystem C losses resulted from soil C losses in deeper horizons, presumably from enhanced decomposition caused by $\mathrm{N}$ addition.

Broader contributions of long-term experiments. Beyond the basic ecological understanding that results from individual experiments, long-term experiments can be valuable by contributing to synthetic activities, testing and inspiring ecological theory and models across systems, and informing policy and management. With respect to synthesis, combining the results of multiple studies in meta-analyses or data syntheses can elucidate how factors such as climate, species composition, and edaphic conditions interact with treatments to influence ecological responses, which adds value to the original, individual experiments. For example, although numerous studies have demonstrated declines in plant species richness in response to $\mathrm{N}$ addition, synthesis of such results across a number of LTER sites revealed that the relative magnitude of species loss varied greatly across sites; warmer sites and those with high cation-exchange-capacity (CEC) soils exhibited lower declines in richness than sites that were colder or had low CEC (Clark et al. 2007). Sites with high abundance of $\mathrm{C}_{4}$ grasses had a greater productivity response to $\mathrm{N}$ addition than did other sites, which was in turn associated with greater proportional declines in species richness.
Long-term experiments conducted at multiple sites, although less common, are particularly powerful ways to achieve general, synthetic understanding of ecological processes. Such studies can identify important influences on ecological processes at large spatial scales. They are more powerful than ad hoc meta-analytical syntheses, because they can eliminate variation in experimental methodologies across sites. For example, the LIDET studied long-term decomposition (10 years) by deploying common substrates across 27 sites, including 16 LTER Network sites (Harmon et al. 2009). The LIDET experiment yielded new insights into decomposition processes including a new understanding of the rates and controls of decomposition of more slowly decomposing litter fractions. Such insights would have been difficult to derive from the meta-analysis of published decomposition studies because most of those studies last one year at most and because substrate variability confounds site-to-site variability in factors such as climate (Adair et al. 2010).

Long-term experiments also take on added value when they inform and are informed by ecological theory and models. Tilman's (1982) study of resource competition that developed the resource-ratio hypothesis of competitive interactions was enriched by the close interplay between long-term experiments and the development of theory at the CDR site. Similarly, empirical research on resource limitation at the ARC site has occurred in close connection with the development of theory on multiple-resource limitation (Herbert et al. 1999). Multiple-resource-limitation theory, in turn, has influenced the development of Earth-system models that explore the implications of $\mathrm{N}$ constraints on $\mathrm{C}$ cycling at a global scale (e.g., Gerber et al. 2010). Given the number and diversity of long-term experiments in the LTER Network, the opportunity certainly exists for additional theory and model development capable of linking a broad array of patterns and processes across temporal and spatial scales.

There are broader practical outcomes of many long-term experiments when they influence the design of policy and management strategies. For example, the litter-exclusion experiment at the CWT site (figure 3 ) clearly demonstrated the importance of tree-leaf litter to the organisms living in headwater streams (Wallace et al. 1997). The importance of maintaining the integrity of headwater streams has been used as an argument against mountaintop mining practices in the central Appalachian region (Meyer and Wallace 2001) and cited in court cases (e.g., P. C. Chambers, US District Judge, Memorandum Opinion and Order on Civil Action No. 3:05-0784 in the Huntington Division of the US District Court of the Southern District of West Virginia, 23 March 2007). Experimental demonstration of the dramatic impacts of deforestation on soil and surface-water chemistry at the HBR site (Bormann et al. 1974) raised awareness of the consequences of intensive forest harvest for environmental quality and influenced the development of best management practices for these forests. Simulations of hurricanes and mortality resulting from pests and pathogens demonstrated that the ecosystem consequences of salvage and 
restoration management of forests-both post-windstorm and in advance of insect infestation or disease-are often much greater than the impacts of the disturbances themselves and led to the argument that leaving forests alone is often a viable management alternative from an ecological perspective (Foster and Orwig 2006). Finally, the results from long-term experiments, coupled with gradient studies, field observations, and data from monitoring networks, have been used to estimate the critical loads of $\mathrm{N}$ for freshwater and terrestrial ecosystems of the United States (Pardo et al. 2011).

Long-term experiments can provide a unique opportunity to directly evaluate the consequences of policy changes using an adaptive-management approach. In adaptivemanagement experiments, the researcher attempts to learn about managed systems by experimentally changing policy and assessing the outcomes on the appropriate time scale. At the NTL site, several policies were enacted as part of a long-term experiment designed to reduce $\mathrm{P}$ inputs and to control algal blooms in Lake Mendota, Wisconsin. Initial changes to land-use practices revealed little effect of management on the P inputs to the lake, possibly because of resuspension of $\mathrm{P}$ stored in sediments. Subsequent manipulation of the Lake Mendota food web to create a trophic cascade was more effective in reducing algal blooms, especially when they were accompanied by fishing-regulation changes and additional land-use practices implemented in the 1990s and 2000s (Carpenter et al. 2006).

Future policy can also be informed by results from long-term experiments. Work at the KBS site suggests that agricultural nitrous oxide $\left(\mathrm{N}_{2} \mathrm{O}\right)$ emissions (figure 3) increase exponentially with increasing rates of $\mathrm{N}$ fertilizer use, after the rates exceed the N-uptake capacity of the crop. In intensive agricultural systems, application of $\mathrm{N}$ in excess of plant needs is rather common, because fertilizer is inexpensive relative to commodity prices, and producers tend to hedge against the risk of insufficient $\mathrm{N}$ in order to achieve maximum yields. Using the concept of maximum return to N, Millar and colleagues (2010) developed a transparent $\mathrm{N}_{2} \mathrm{O}$-reduction protocol suitable for incentivizing $\mathrm{N}_{2} \mathrm{O}$ reductions without affecting crop yields. They estimated that if the protocol were widely adopted as a part of future $\mathrm{C}$ cap-and-trade markets, the protocol could reduce $\mathrm{N}_{2} \mathrm{O}$ from fertilized row-crop agriculture by more than $50 \%$.

Long-term experiments as platforms for new and unplanned research. Because of their multiyear nature, long-term experiments can serve as platforms for research that go well beyond the goals originally envisioned. As a result, they provide opportunities for novel studies that take advantage of imposed treatments, as well as for more detailed process-level studies to uncover mechanisms behind longterm patterns. For example, the soil-warming studies at the HFR site have become a platform for new studies of soil $\mathrm{N}$; the consequences of garlic mustard invasion, an exotic species that inhibits mycorrhizae and the growth of some tree seedlings; and for microbial studies of the mechanisms responsible for the pattern of increased heterotrophic soil respiration followed by a diminishing response to warming (Bradford et al. 2008). This latter research showed that the apparent acclimation of soil respiration at the ecosystem scale results from the combined effects of reductions in soil $\mathrm{C}$ pools and microbial biomass and changes in the thermal response of microbial respiration. Mass-specific respiration rates were lower when seasonal temperatures were higher, which suggests that rate reductions under experimental warming probably occurred through temperature-induced changes in the microbial community.

The long-term nutrient-addition studies that were conducted at multiple LTER sites to understand the role of $\mathrm{N}$ limitation, as well as to test ecosystem response to enhanced $\mathrm{N}$ deposition, have similarly provided a rich template for more short-term mechanistic studies. At the NWT site, for example, these studies have identified the importance of plant species traits in affecting community change (Suding et al. 2006) and demonstrated how plant-microbial feedbacks influence species coexistence (Ashton et al. 2008). Experiments initially designed to study vegetation change have been used to provide important insights as to how increased $\mathrm{N}$ availability can affect soil C storage (Neff et al. 2002).

Long-term experiments are increasingly serving as platforms for ecological metagenomics studies. At the SEV site, for example, microbial ecologists are examining the metagenomic responses of rhizosphere microbes in a fully crossed multifactor experiment that includes increased winter rainfall, $\mathrm{N}$ amendment, and nighttime warming (Collins et al. 2010). At the CDR site, metagenomic studies have shown a marked divergence of microbial communities in grassland communities developed under ambient as opposed to elevated $\mathrm{CO}_{2}$ in terms of both composition and function, with communities under elevated $\mathrm{CO}_{2}$ exhibiting increased abundances of the genes involved in labile $\mathrm{C}$ decomposition and $\mathrm{C}$ and $\mathrm{N}$ fixation (He et al. 2010).

A call for a new generation of long-term experiments We have argued that well-designed long-term experiments focused on key questions and important processes can have tremendous value for individual sites. These long-term experiments can provide the understanding necessary for forecasting, coping with, and mitigating the consequences of human-driven global changes to the environment (Collins et al. 2011). However, the scope and pace of change occurring in ecological systems today-and forecast for the futureare, by all accounts, unprecedented in human history (Palmer et al. 2004, Solomon et al. 2007, Smith et al. 2009). Because of the global scale of altered biogeochemical cycles from increased atmospheric $\mathrm{CO}_{2}$ concentrations, nutrient enrichment and depletion, climatic change (means and extremes; Smith 2011), exotic species introductions, and land-use change, all ecosystems are, and will continue to be, affected by these alterations (Solomon et al. 2007). Independently conducted site-based studies in which global-change factors 
(i.e., $\mathrm{N}$ or temperature) were manipulated and modeling studies both show that responses to these global-change factors may vary dramatically among ecosystems-from little or no response to a substantial change in function (e.g., Weltzin et al. 2003). But experimental ecologists need to think beyond the site level and provide a more complete understanding of how and why ecosystems differ in their susceptibility and sensitivity to these changes. Such understanding is critical for forecasting the ecological consequences of global change at regional to continental spatial scales and yet it is a challenge that ecologists have not fully met (Smith et al. 2009).

This lack of comprehensive understanding occurs, in part, because ecologists have historically conducted disparate, largely independent experiments that tend to differ markedly with regard to (a) what is manipulated, (b) how much and for how long manipulations occur, and (c) what (and how) response variables are measured. This is certainly true of long-term experiments conducted in the LTER Network. As a result, syntheses across these studies can be difficult, since there is no way of knowing how much these different approaches contribute to the range of responses observed among ecosystems (Knapp et al. 2004). As Callahan (1984) pointed out more than 25 years ago, "even similar projects are not often comparable unless effort and resources have been devoted to making them so. This inherent tendency away from comparability becomes more prominent among projects conducted at locations that are geographically and biologically disjunct" (p. 363). Recently, renewed calls have been made for establishing unified sampling protocols and conducting simultaneous multisite, multifactor experiments to address the most pressing global-change issues (Janzen 2009, Luo et al. 2011; e.g., The Nutrient Network, http://nutnet.science.oregonstate.edu). We echo and extend these calls by proposing that these multisite experiments should be planned as long-term experiments capable of elucidating both ecological dynamics and ecological mechanisms. As is appropriate, these should take advantage of the long-term observations and contextual understanding extant within the LTER Network as well as from nonnetwork sites and other existing and emerging observatories (Carpenter 2008, Robertson et al. 2012 [in this issue]).

Designing multisite experiments will not be without challenges. For example, how one scales treatment levels across disparate ecosystems can influence how these different ecosystems respond to "common treatments." For experiments that alter $\mathrm{CO}_{2}$, treatments can be designed to increase $\mathrm{CO}_{2}$ by either a constant amount or a constant proportion with an expectation of comparable results because essentially all terrestrial ecosystems have very similar atmospheric $\mathrm{CO}_{2}$ concentrations. But for resources such as water and $\mathrm{N}$, initial stocks and turnover rates can vary by orders of magnitude among mesic or xeric and fertile or infertile ecosystems. Therefore, experiments designed to increase or decrease resources by a constant proportion of availability and those designed to change them by a constant amount will likely lead to very different responses among sites. As was noted above, long-term data from observations and monitoring at LTER sites and the rich array of shorter-term processlevel studies that each site has conducted can be invaluable for providing the appropriate context for planning such experiments, as well as for interpreting their results. Longterm data can also provide the breadth of understanding necessary for devising more-detailed studies that are often necessary for elucidating key mechanisms. Other issues that must be addressed, and that LTER scientists grapple with today, include determining the end point for long-term experiments (e.g., when do the costs outweigh the new knowledge gained by continuing an experiment?) and how to optimally balance the trade-off between the spatial scale of manipulations and the number of replicates. Small-plotbased long-term experiments, such as those at the CDR site, can be designed to be statistically robust with many replicates. This is not feasible with large-scale whole-watershed manipulations, such as those at the HBR site (figure 1). The scale of manipulations also determines the degree to which long-term experiments can serve as platforms for additional research. These are important tradeoffs in design that need to be considered for future long-term experiments.

We further advocate that such multisite long-term experiments should be designed in close collaboration with ecological modelers in order to alleviate the more vexing uncertainties in today's models (Luo et al. 2011). Scenario planning (Peterson et al. 2003) can also be a valuable tool for designing experiments capable of providing information relevant to stakeholders in addition to ecologists. These longterm experiments should be as large in scale as is feasible in order to permit the evaluation of ecological processes not possible in small-plot experiments (Smith et al. 2009). Designing large-scale experiments will present many unique challenges, since they are not simply big versions of the small-scale manipulations that ecologists have conducted in the past. Innovation in experimental design, statistical analysis, and engineering will be necessary. But, as was noted above, with space set aside to accommodate unanticipated use, these networks of large-scale experiments would also serve as valuable research platforms for the broader ecological community. A highly coordinated and spatially extensive network of multifactor long-term experiments that adopts such a comparative approach would provide understanding and quantitative response data on ecological change at a temporal and spatial scale heretofore unavailable to ecologists. Such a network of experiments would complement the monitoring-based approach that the emerging National Ecological Observatory Network (NEON) has adopted by providing experimentally defined units of accelerated or amplified ecological change. Data from multisite, long-term experiments can be fused with models (Luo et al. 2011) to make more robust forecasts for a broad range of ecosystems. Such forecasts can then be tested against the real-time tracking of ecological change provided by NEON infrastructure and other observatory networks - and, of course, by the LTER Network. 
For long-term experimental networks as they are envisioned above to be realized, it is clear that clever designs, collaborations between ecologists and sensor and infrastructure engineers (Collins et al. 2006), and efficient deployment will be necessary from both scientific and economic perspectives. But as society demands the knowledge needed to cope with and mitigate global changes, ecologists would be remiss in forgoing the opportunity to build on the legacy of long-term experiments reviewed above to meet these challenges.

\section{Acknowledgments}

We thank the principal investigators of the 26 Long Term Ecological Research Network sites for providing information regarding long-term experiments at their sites, Steve Carpenter and Tim Kratz for insight regarding North Temperate Lake-site experiments, and David Foster for providing editorial input and oversight. Robert Holt, Charles Driscoll, and an anonymous reviewer provided helpful comments on an earlier version of the manuscript.

\section{References cited}

$\rightarrow$ Adair EC, Hobbie SE, Hobbie RK. 2010. Single-pool exponential decomposition models: Potential pitfalls in their use in ecological studies. Ecology 91: 1225-1236.

$\rightarrow$ Ashton IW, Miller AE, Bowman WD, Suding KN. 2006. Nitrogen preferences and plant-soil feedbacks as influenced by neighbors in the alpine tundra. Oecologia 156: 625-636.

$\rightarrow$ Báez S, Collins SL, Lightfoot D, Koontz TL. 2006. Bottom-up regulation of plant community structure in an aridland ecosystem. Ecology 87: 2746-2754.

$\rightarrow$ Blair JM. 1997. Fire, $N$ availability and plant response in grasslands: A test of the transient maxima hypothesis. Ecology 78: 2359-2368.

$\rightarrow$ Bormann FH, Likens GE, Siccama TG, Pierce RS, Eaton JS. 1974. The export of nutrients and recovery of stable conditions following deforestation at Hubbard Brook. Ecological Monographs 44: 255-277.

$\rightarrow$ Bradford MA, Davies CA, Frey SD, Maddox TR, Melillo JM, Mohan JE, Reynolds JF, Treseder KK, Wallenstein MD. 2008. Thermal adaptation of soil microbial respiration to elevated temperature. Ecology Letters 11: 1316-1327.

$\rightarrow$ Brown JH, Heske EJ. 1990. Control of a desert-grassland transition by a keystone rodent guild. Science 250: 1705-1707.

$\rightarrow$ Callahan JT. 1984. Long-term ecological research. BioScience 34: 363-367.

$\rightarrow$ Carpenter SR. 2002. Ecological futures: Building an ecology of the long now. Ecology 83: 2069-2083.

$\rightarrow-$. 2008. Emergence of ecological networks. Frontiers in Ecology 6: 228.

Carpenter SR, Lathrop RC, Nowak P, Bennett EM, Reed T, Soranno PA. 2006. The ongoing experiment: Restoration of Lake Mendota and its watershed. Pages 236-256 in Magnuson JJ, Kratz TK, Benson BJ, eds. Long-Term Dynamics of Lakes in the Landscape. Oxford University Press.

$\rightarrow$ Chapin FS III, Shaver GR, Giblin AE, Nadelhoffer KJ, Laundre JA. 1995. Responses of arctic tundra to experimental and observed changes in climate. Ecology 76: 694-711.

$\rightarrow$ Clark CM, Cleland EE, Collins SL, Fargione JE, Gough L, Gross KL, Pennings SC, Suding KN, Grace JB. 2007. Environmental and plant community determinants of species loss following nitrogen enrichment. Ecology Letters 10: 596-607.

$\rightarrow$ Collins SL, et al. 2006. New opportunities in ecological sensing using wireless sensor networks. Frontiers in Ecology and the Environment 4: 402-407.

Collins SL, Fargione JE, Crenshaw CL, Nonaka E, Elliott JR, Xia Y, Pockman WT. 2010. Rapid plant community responses during the summer monsoon to nighttime warming in a northern Chihauhuan Desert grassland. Journal of Arid Environments 74: 611-617.

Collins SL, et al. 2011. An integrated conceptual framework for long-term social-ecological research. Frontiers in Ecology and the Environment 9: 351-357.

Contosta AR, Frey SD, Cooper AB. 2011. Seasonal dynamics of soil respiration and $\mathrm{N}$ mineralization in chronically warmed and fertilized soils. Ecosphere 2 (3, Art. 36).

Costamagna AC, Landis DA. 2006. Predators exert top-down control of soybean aphid across a gradient of agricultural management systems. Ecological Applications 16: 1619-1628.

Dasch AA, Blum JD, Eagar C, Fahey TJ, Driscoll CT, Siccama TG. 2006. The relative uptake of $\mathrm{Ca}$ and $\mathrm{Sr}$ into tree foliage using a whole-watershed calcium addition. Biogeochemistry 80: 21-41.

Debinski DM, Holt RD. 2000. A survey and overview of habitat fragmentation experiments. Conservation Biology 14: 342-355.

Franklin JF, Bledsoe CS, Callahan JT. 1990. Contributions of the long-term ecological research program. BioScience 40: 509-523.

Frost TM, Fischer JM, Klug JL, Arnott SE, Montz PK. 2006. Trajectories of zooplankton recovery in the Little Rock Lake whole-lake acidification experiment. Ecological Applications 16: 353-367.

Foster DR, Orwig DA. 2006. Preemptive and salvage harvesting of New England forests: When doing nothing is a viable alternative. Conservation Biology 20: 959-970.

Foster DR, Aber JD, Melillo JM, Bowden RD, Bazzaz FA. 1997. Forest response to disturbance and anthropogenic stress: Rethinking the 1938 Hurricane and the impact of physical disturbance vs. chemical and climate stress on forest ecosystems. BioScience 47: 437-445.

Gardiner MM, Landis DA, Gratton C, DiFonzo CD, O'Neal M, Chacon JM, Wayo MT, Schmidt NP, Mueller EE, Heimpel GE. 2009. Landscape diversity enhances the biological control of an introduced crop pest in the north-central U.S. Ecological Applications 19: 143-154.

Gerber S, Hedin LO, Oppenheimer M, Pacala SW, Shevliakova E. 2010. Nitrogen cycling and feedbacks in a global dynamic land model. Global Biogeochemical Cycles 24 (Art. GB1001). doi:10.1029/2008GB003336

Gonzalez MJ, Frost TM. 1994. Comparisons of laboratory bioassays and a whole-lake experiment: Rotifer responses to experimental acidification. Ecological Applications 4: 69-80.

Harmon ME, Silver WL, Fasth B, Chen H, Burke IC, Parton WJ, Hart SC, Currie WS, LIDET. 2009. Long-term patterns of mass loss during the decomposition of leaf and fine root litter: An intersite comparison. Global Change Biology 15: 1320-1338.

He Z, Xu M, Deng Y, Kang S, Kellogg L, Wu L, Van Nostrand JD, Hobbie SE, Reich PB, Zhou J. 2010. Metagenomic analysis reveals a marked divergence in the structure of belowground microbial communities at elevated $\mathrm{CO}_{2}$. Ecology Letters 13: 564-575.

Heimpel GE, Frelich LE, Landis DA, Hopper KR, Hoelmer K, Sezen Z, Asplen MK, Wu K. 2010. European buckthorn and Asian soybean aphid as part of an extensive invasional meltdown in North America. Biological Invasions 12: 2913-2931.

Herbert DA, Rastetter EB, Shaver GR, Ågren GI. 1999. Effects of plant growth characteristics on biogeochemistry and community composition in a changing climate. Ecosystems 2: 367-382.

Hobbie JE, Carpenter SR, Grimm NB, Gosz JR, Seastedt TR. 2003. The US long-term ecological research program. BioScience 53: 21-32.

Huggett BA, Schaberg PG, Hawley GJ, Eagar C. 2007. Long-term calcium addition increases growth release, wound closure, and health of sugar maple (Acer saccharum) trees at the Hubbard Brook Experimental Forest. Canadian Journal of Forest Research 37: 1692-1700.

Janzen HH. 2009. Long-term ecological sites: Musings on the future, as seen (dimly) from the past. Global Change Biology 15: 2770-2778.

Juice SM, Fahey TJ, Siccama TG, Driscoll CT, Denny EG, Eagar C, Cleavitt NL, Minocha R, Richardson AD. 2006. Response of sugar maple to calcium addition to northern hardwood forest. Ecology 87: 1267-1280.

Knapp AK, Briggs JM, Hartnett DC, Collins SL. 1998. Grassland Dynamics: Long-Term Ecological Research in Tallgrass Prairie. Oxford University Press. 
Knapp AK, et al. 2004. Searching for generality in ecology: Post-hoc synthesis of long-term data from North American grasslands and South African savannas. Frontiers in Ecology and the Environment 2: 483-491.

Likens GE, Driscoll CT, Buso DC. 1996. Long-term effects of acid rain: Response and recovery of a forest ecosystem. Science 272: 244-246.

Lindenmayer DB, Likens GE, Krebs CJ, Hobbs RJ. 2010. Improved probability of detection of ecological "surprises." Proceedings of the National Academy of Sciences 107: 21957-21962.

Luo Y, et al. 2011. Coordinated approaches to quantify long-term ecosystem dynamics in response to global change. Global Change Biology 17: 843-854.

Mack MC, Schuur EAG, Bret-Harte MS, Shaver GR, Chapin FS III. 2004. Ecosystem carbon storage in arctic tundra reduced by long-term nutrient fertilization. Nature 431: 440-443.

Melillo JM, Steudler PA, Aber JD, Newkirk K, Lux H, Bowles FP, Cartricala C, Magill AH, Ahrens T, Morrisseau S. 2002. Soil warming and carboncycle feedbacks to the climate system. Science 298: 2173-2176.

Meserve PL, Kelt DA, Milstead WB, Gutiérrez JR. 2003. Thirteen years of shifting top-down and bottom-up control. BioScience 53: 633-646.

Meyer JL, Wallace JB. 2001. Lost linkages and lotic ecology: Rediscovering small streams. Pages 295-317 in Press MC, Huntly NJ, Levin S, eds. Ecology: Achievement and Challenge. Blackwell Science.

Millar N, Robertson GP, Grace PR, Gehl RJ, Hoben JP. 2010. Nitrogen fertilizer management for nitrous oxide $\left(\mathrm{N}_{2} \mathrm{O}\right)$ mitigation in intensive corn (Maize) production: An emissions reduction protocol for US Midwest agriculture. Mitigation and Adaptation Strategies for Global Change 15: 185-204.

Neff JC, Townsend AR, Gleixner G, Lehman SJ, Turnbull J, Bowman WD. 2002. Variable effects of nitrogen additions on the stability and turnover of soil carbon. Nature 419: 915-917.

[NRC] National Research Council. 2001. Grand Challenges in Environmental Sciences. National Academies Press.

Odum EP. 1977. The emergence of ecology as a new integrative discipline. Science 195: 1289-1293.

Pardo LH, et al. 2011. Effects of nitrogen deposition and empirical nitrogen critical loads for ecoregions of the United States. Ecological Applications 21: 3049-3082.

Peterson GD, Cumming GS, Carpenter SR. 2003. Scenario planning: A tool for conservation in an uncertain future. Conservation Biology 17: 358-366.

Rees M, Condit R, Crawley M, Pacala S, Tilman D. 2001. Long-term studies of vegetation dynamics. Science 293: 650-655.

Reich PB, Hobbie SE, Lee T, Ellsworth DS, West JB, Tilman D, Knops JMH, Naeem S, Trost J. 2006. Nitrogen limitation constrains sustainability of ecosystem response to $\mathrm{CO}_{2}$. Nature 440: 922-925.

Robertson GP, et al. 2012. Long-term ecological research in a humandominated world. BioScience 62: 342-353.

Slavik K, Peterson BJ, Deegan LA, Bowden WB, Hershey AE, Hobbie JE. 2004. Long-term responses of the Kuparuk River ecosystem to phosphorus fertilization. Ecology 85: 939-954.
Smith MD. 2011. An ecological perspective on extreme climatic events: A synthetic definition and framework to guide future research. Journal of Ecology 99: 656-663.

Smith MD, Knapp AK, Collins SL. 2009. A framework for assessing ecosystem dynamics in response to chronic resource alterations induced by global change. Ecology 30: 3279-3289.

Solomon SD, Qin M, Manning Z, Chen M, Marquis KB, Avery T, Tignor M, Miller HL, eds. 2007. Climate Change 2007: The Physical Science Basis. Cambridge University Press.

Suding KN, Miller A, Bechtold H, Bowman W. 2006. The consequences of species loss on ecosystem nitrogen cycling depends on community composition dynamics. Oecologia 149: 141-149.

Syswerda SP, Basso B, Hamilton SK, Tausig JB, Robertson GP. 2012. Long-term nitrate loss along an agricultural intensity gradient in the upper Midwest USA. Agriculture, Ecosystems and Environment 149: $10-19$.

Tilman D. 1982. Resource Competition and Community Structure. Princeton University Press. . 1989. Ecological experimentation: Strengths and conceptual problems. Pages 136-157 in Likens GE, ed. Long-Term Studies in Ecology. Springer.

. 1996. Biodiversity: Population versus ecosystem stability. Ecology 77: $350-363$.

$\rightarrow$ Wallace JB, Eggert SL, Meyer JL, Webster JR. 1997. Multiple trophic levels of a forest stream linked to terrestrial litter inputs. Science 277: 102-104.

Weltzin JF, et al. 2003. Assessing the response of terrestrial ecosystems to potential changes in precipitation. BioScience 53: 941-952.

Yeakley JA, Coleman DC, Haines BL, Kloeppel BD, Meyer JL, Swank WT, Argo BW, Deal JM, Taylor SF. 2003. Hillslope nutrient dynamics following upland riparian vegetation disturbance. Ecosystems 6: 154-167.

Alan K. Knapp (aknapp@colostate.edu) is affiliated with the Graduate Degree Program in Ecology and with the Department of Biology at Colorado State University, Fort Collins. Melinda D. Smith and Kimberly J. La Pierre are affiliated with the Department of Ecology and Evolutionary Biology at Yale University, in New Haven, Connecticut. Sarah E. Hobbie is affiliated with the Department of Ecology, Evolution and Behavior at the University of Minnesota, St. Paul. Scott L. Collins is affiliated with the Department of Biology at the University of New Mexico, in Albuquerque. Timothy J. Fahey is affiliated with the Department of Natural Resources at Cornell University, in Ithaca, New York. Gretchen J. A. Hansen is affiliated with the Center for Limnology at the University of Wisconsin-Madison. Douglas A. Landis is affiliated with the Department of Entomology and with the Great Lakes Bioenergy Research Center at Michigan State University, in East Lansing. Jerry M. Melillo and Gaius R. Shaver are affiliated with The Ecosystems Center, Marine Biological Laboratory, in Woods Hole, Massachusetts. Timothy R. Seastedt is affiliated with the Department of Ecology and Evolutionary Biology and with the Institute of Arctic and Alpine Research, at the University of Colorado, Boulder. Jackson R. Webster is affiliated with the Department of Biological Sciences at Virginia Tech, Blacksburg. 